\section{Schema utilization in pattern perception}

ELVIS C. JONES' and J. RICHARD HOLLEY, Augusta College, Augusta, Ga. 30904

In a pattern-reproduction task, Ss demonstrated "schema-plus-correction" encoding. The manner in which the patterns were constructed eliminated the possibility that schemata are used only as a "better-than-chance guess" (reproduction of the schema when the specific patterns are not retained).

Schema learning consists of the abstraction from a population of stimuli those characteristics that define the population (Attneave, 1957). Schema learning normally occurs when the learner attempts to simplify his memory task by identifying the population to which a stimulus belongs and noting features of the stimulus that are distinctive (Woodworth, 1938).

The fact that normal humans can abstract schemata has been demonstrated repeatedly. It has been found that schema learning can occur without exposure to the population prototype and without knowledge of results (e.g., Edmonds, Mueller, \& Evans, 1966).

Unfortunately, abstracting a schema does not necessarily guarantee that the schema will be used. Furthermore, an abstracted schema can often be used in more than one way. The present paper is concerned only with the use of schemata as a basis for economical encoding of patterns in reproduction tasks. Knowledge of a schema can be used as a retention aid either to (1) focus memory effort on those details of a pattern that are distinctive of the pattern, or (2) provide a "better-than-chance guess" about those parts of the pattern that are not retained. The first use occurs during memorization, the second use, during reproduction.

Schema utilization in the sense of (1), above, has been called "schema plus correction" $(\mathrm{S}+\mathrm{C})$ and may be conceptualized as a partitioning of a pattern into two components (Evans, 1967). One component consists of those parts of the pattern that belong to and conform to the schema. This component may be called the schematic component (S). In the case of VARGUS 9 histoform patterns (Evans \& Mueller, 1966), this component corresponds to those columns in a specific pattern that are equal to the average height for the column. The other component consists of those parts of the patterns that do not belong to or that deviate from the schema. This component may be called the nonschematic component, or the "correction" (C). In VARGUS 9 histoform patterns, this component corresponds to those columns that are not equal to the average height for the column or to those columns that are not a part of the schema.

After partitioning the pattern into the $S$ and $C$ components, an individual who has learned the schema can memorize the pattern efficiently by identifying the $S$ portion (viz, determine which columns conform to the schema), and then rote-memorize the $\mathrm{C}$ portion of the pattern. Thus, his task of memorizing is primarily restricted to the portion of the pattern that is distinctive of the pattern (the $\mathrm{C}$ portion). He can recover the $\mathrm{S}$ portion of any individual pattern by recovering the schema that is common to all patterns and that need not be memorized anew with each new pattern.

Schema utilization in the sense of (2), above, can occur in those cases where a set of patterns is extremely complex. In these cases, the learner may feel quite satisfied in being able merely to abstract the $S$ portion of a pattern and reproduce it in the time allotted. He may not have the time or capacity to do more. Furthermore, in some cases the schema itself may be so complex that an individual will be unable to learn all of it. In such a case, he will profit more by attending to the $S$ portion than to the $C$ portions since a knowledge of the $S$ portion will aid his reproduction of all patterns, whereas memorization of the $\mathrm{C}$ portion of one pattern will not aid him on other patterns. Although this form of schema utilization is superior to using no schema, it is not as efficient as the $\mathrm{S}+\mathrm{C}$ method since part or all of the columns that were rote-memorized may have been schematic and need not have been memorized.

In reproduction tasks employing VARGUS 9 patterns, the "better-than-chance guess" method could occur as follows: After the learner has abstracted the schema (viz, the average height of each column), he may simply reproduce the schema itself, paying little or no attention to the fact that some column in a pattern may deviate from the average height for that column. Using this strategy, a learner's performance could improve from chance to a high level of accuracy. With highly redundant patterns, his reproductions may be correct most of the time simply because each column will be at the height that is average for that column in most of the patterns. In highly redundant VARGUS 9 patterns, it is not unusual for the average height for a column to occur on more than $80 \%$ of the patterns. In such cases, the learner could be correct more than $80 \%$ of the time by simply reproducing the schema on each trial.

If Schema Theory ${ }^{2}$ is to fulfill its promise, it must be shown that $\mathrm{S}+\mathrm{C}$ encoding does occur. Schema learning and utilization in the sense of providing a "better-than-chance guess," can be adequately accounted for by a variety of theories (e.g., Hull's (1943) concept of summation of generalized habit strength, Helson's (1959) AL theory, etc.). In fact, if this were the only form of schema utilization, the existence of Schema Theory may not be justified. On the other hand, if it can be shown that schema utilization in the $\mathrm{S}+\mathrm{C}$ sense occurs, then Schema Theory may be able to account for a variety of phenomena that other approaches have not touched upon, although this remains to be seen.

Demonstrating $\mathrm{S}+\mathrm{C}$ encoding is not as simple as might at first be imagined. It is often impossible to rule out the possibility that performance improvements may be due to a "better-than-chance guessing" procedure.

Nevertheless, S + C encoding may be demonstrated with VARGUS 9 patterns by arranging a reproduction task in which some columns are always random and other columns always conform to the schema. If the learner is forced to memorize the entire pattern, then the fact that part of the pattern is schematic should allow those who have learned the schema to encode and retain the $C$ portion better. On the other hand, Ss who are trained with patterns that are entirely nonschematic cannot utilize $\mathrm{S}+\mathrm{C}$. They must attempt to rote-memorize all of the columns in each pattern.

If the random columns (upon which retention is to be measured) are the same for both groups, then the groups would differ only in that the other columns in each pattern must be learned anew on each trial by one group (the $\mathrm{C}$ group) but are identical on all trials for the other group (the $\mathrm{S}+\mathrm{C}$ group) and need be learned only once. Furthermore, performance improvements during training cannot be explained by a "better-than-chance guessing" strategy since no guessing strategy could produce better-than-chance performance on random columns.

\section{METHOD}

The Ss were 20 experimentally naive undergraduate students, randomly assigned to two groups of $10 \mathrm{Ss}$.

The stimuli were 30 histoform patterns produced by typing columns of zeros on a 


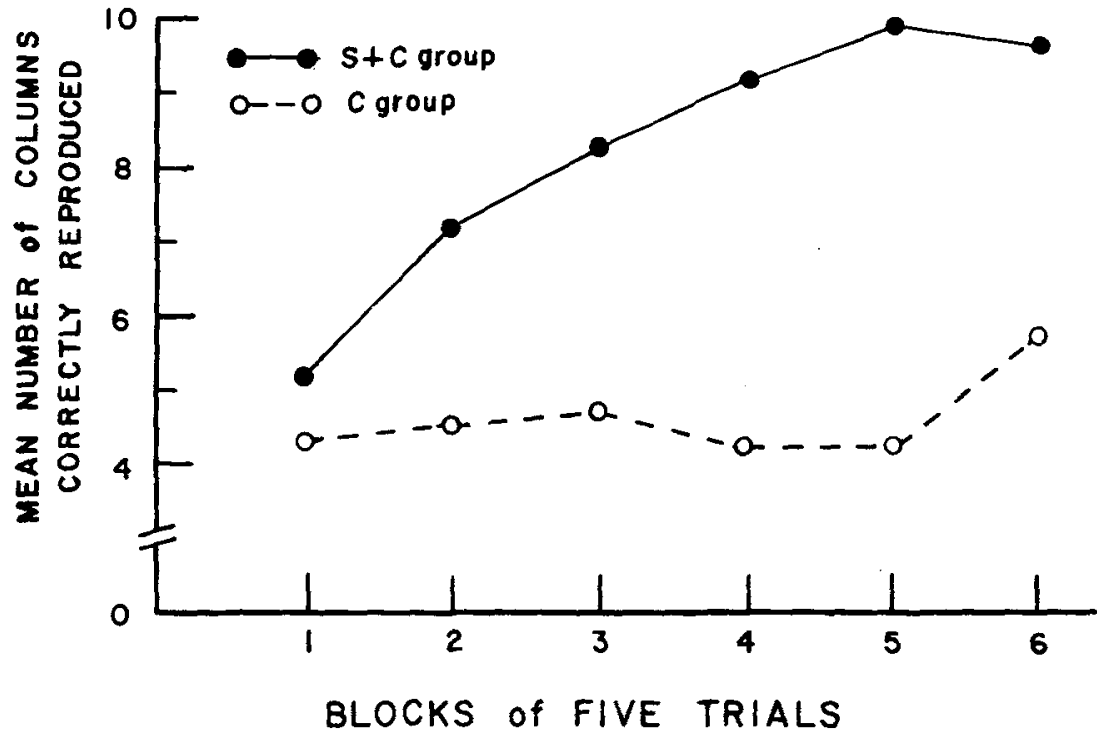

Model 11 IBM typewriter. Each pattern consisted of 12 columns, with possible column heights ranging from 1 to 15 units. The first four columns were identical in the patterns that both groups received. The heights of these columns were determined randomly for each pattern. The probability of guessing correctly one of the first four column heights was, therefore, $1 / 15$.

The last eight columns were always set at the following heights for the $\mathrm{S}+\mathrm{C}$ group: $4,6,8,10,12,11,9,7$. For the $C$ group, 30 randomly selected permutations of these eight column heights were used. Thus, both groups reproduced the same column heights, except that the sequences of the last eight column heights was always the same for the $S+C$ group but varied for the $\mathrm{C}$ group. For the $\mathrm{C}$ group, the probability of guessing one of the last eight column heights, assuming that they had learned the possible heights, was $1 / 8$. It should be noted that the patterns reproduced by the $\mathrm{C}$ group were not entirely random, the last eight columns being roughly $50 \%$ redundant (Attneave, 1959).

Each learner received a mimeographed booklet containing the 30 patterns and 30 test pages. Blackened sheets were inserted between each pattern and test page to prohibit the Ss from seeing the preceding or following page. On each trial, the learner was allowed to view the pattern for $15 \mathrm{sec}$ and then was allowed $30 \mathrm{sec}$ in which to reproduce the pattern. On each test page, six randomly selected columns were omitted; two from among the first four columns and four from the last six columns. Scoring was restricted to the two columns omitted from the first four columns. Knowledge of results was not provided and the order of the patterns was not counterbalanced. Previous use of the same patterns had indicated that there was data analysis.

\section{RESULTS AND DISCUSSION} columns vs four). alternative approaches. others).

\section{REFERENCES}

Fig. 1. Performance over 30 trials as a function of opportunity to utilize "schema-plus-correction" encoding in the retention of histoform patterns.

ATTNEAVE, F. Transfer of experience with a class-schema to identification-learning of patterns and shapes. Journal of Experimental Psychology, 1957, 54, 81-88.

ATTNEAVE, F. Application of information theory to psychology. New York: Holt, Rinehart \& Winston, 1959.

ATTNEAVE, F. In defense of Homunculi. In W. A. Rosenblith (Ed.), Sensory communication. Cambridge, Mass: The M.1.T. Press, 1961.

BARTLETT, F. C. Remembering: $A$ study in experimental and social psychology. London: Cambridge University Press, 1932.

BROWN, R. Words and things. New York: The Free Press, 1958.

BRUNER, J. S. Neural mechanisms in perception. Psychological Review, 1957a, 64, 340-358.

BRUNER, J. S, On perceptual readiness. Psychological Review, 1957b, 64, 123-152.

no significant difference in the difficulty of the five trial blocks that were used in the

As indicated in Fig. 1, the performance of the $\mathrm{S}+\mathrm{C}$ group was superior to that of the $C$ group. A comparison of the total number of columns correctly reproduced was significant $(F=15.755, \mathrm{df}=1 / 18$, $\mathrm{p}<.001)$. Not shown in Fig. 1 is the fact that, on the first trial, the $C$ group's performance was superior to that of the $S+C$ group (a total of seven correct

A repeated-measures trend analysis (Edwards, 1960) over blocks of five trials resulted in a significant trials effect $(F=4.019$, df $=5 / 90, \mathrm{p}<.005)$ and a significant Groups by Trials interaction $(\mathrm{F}=2.913, \quad \mathrm{df}=5 / 90, \quad \mathrm{p}<.01) . \quad$ The Groups by Trials interaction is primarily accounted for by the improvement in the $S+C$ group's performance, while the C group demonstrated little if any improvement until the last block of trials.

The results strongly indicate that schema utilization in the $S+C$ sense does occur. This demonstration strengthens the foundation of Schema Theory and, as noted earlier, may serve to differentiate the predictions of Schema Theory from some

The $S+C$ patterns used in the present study may be useful in extending research into areas that have previously been considered impractical. They could be used, for example, in quantitative studies of phenomena that were previously dealt with on a qualitative basis (e.g., the memory studies of Bartlett (1932) and

ATTNEAVE, F. Some informational aspects of visual perception. Psychological Review, 1954 . 61, 183-193.
EDMONDS, E. M., MUELLER, M. R., \& EVANS, S. H. Effects of knowledge of results on mixed schema discrimination. Psychonomic Science, 1966, 6, 377-378.

EDWARDS, A. L. Experimental design in psychological research. New York: Holt. Rinehart. \& Winston, 1960.

EVANS, S. H. A brief statement of schema theory. Psychonomic Science, 1967, 8, 87-88.

EVANS. S. H., \& MUELLER, M. R. VARGUS 9: Computed stimuli for shema research. Psychonomic Science, 1966, 6, 511-512.

HELSON, H. Adaptation level theory. In Koch, S. (Ed.), Psychologi: a study of a science. Vol. 1. New York: IfCirau-Hill. 1959.

HULL. C. L. Principle's of heharior. New York: Appleton-Century-('rotts. 1943.

OLDFIELD, R. C. Memory mechanisms and the theory of schemata. British Journal of Psychology, 1954, 45, 14-23.

OLDFIELD, R. C., \& ZANGWILL, O. L. Head's concept of the schema and its application in contemporary British psychology. British Joumal of Psychology. 1942, 32, 267-286: $1943,33,58-64,113-129$, and 143-149.

PICK, A. D. Improvement of visual and tactual form discrimination. Journal of Experimental Psychology, 1965, 69, 331-339.

SOLLEY, C. M., \& MURPHY, G. Development of the perceptual world. Ncw York: Basic Books, 1960.

VERNON, M. D. A further study of visual perception. London: Cambridge University Press, 1952.

VERNON, M. D. The functions of schemata in perceiving. Psychological Review, 1955, 62, 180-192.

WOODWORTH, R. S. Experimental psychology. New York: Holt. 1938.

\section{NOTES}

1. Now at Irostburg State College, Frostburg, Md. 21532.

2. "Schema theory" is not yet a coherent, easily distinguishable set of postulates. Rather, it is mostly a focus of interest and a general approach in the study of perceptual learning and retention. In addition to the references used in the body of this article, other related works include Brown (1958, especially Chapter 3$)$. Bruner (1957a, b), Pjck (1965), Vernon (1952, 1955), Solley \& Murphy (1960), Attneave (1954, 1961), Oldfield (1954), and Oldfield \& Zangwill (1942). Not all of these writers have used the term "schema," but the referent scems to be the same. Psychon. Sci., 1970, Vol. 18 (4) 